\title{
Research Paper: Parental Traits in the Relationship of Type and Severity of Psychopathology in Young Adults
}

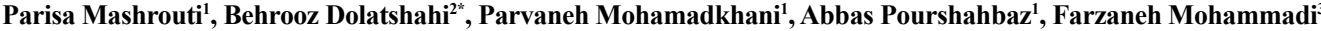 \\ 1. Department of Clinical Psychology, University of Social Welfare and Rehabilitation Sciences, Tehran, Iran. \\ 2. Substance Abuse and Dependence Research Center, University of Social Welfare and Rehabilitation Sciences, Tehran, Iran. \\ 3. Department of Psychology, School of Medicine, Shahid Beheshti University of Medical Sciences, Tehran, Iran.
}

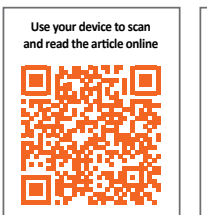

ditation: Mashrouti, P., Dolatshahi, B., Mohamadkhani, P., Pourshahbaz, A., \& Mohammadi, F. (2017). Parental Traits in the Relationship of Type and Severity of Psychopathology in Young Adults. Journal of Practice in Clinical Psychology, 5(4), $297-304$. https://doi.org/10.29252/NIRP.JPCP.5.4.297

\section{https://doi.org/10.29252/NIRP.JPCP.5.4.297}

\section{Article info:}

Received: 120 Mar. 2017

Accepted: 24 Jun. 2017

\section{Keywords:}

Psychopathology, Anxiety, Depression, Parent-child relations

\section{ABSTRACT}

Objective: Early year experiences with parents play an important role in the development of personality of individuals. In this regard, the present study aimed at assessing the relationship between parental bonding and type and severity of psychopathology in young adults.

Methods: A total of 361 students ( 205 boys and 156 girls) of Tabriz University were selected by cluster sampling method and then tested by Parental Bonding Inventory (PBI) and Symptom Check List-90-R (SCL-90-R). Finally, the obtained data were analyzed using Pearson correlation coefficient and hierarchical regression with SPSS v.16 software.

Results: The results showed that maternal and paternal care have a significantly negative correlation with the general suffering scales. The correlation of maternal care is stronger than the paternal care. Also, paternal overprotection has the strongest correlation with general severity scales. Regression results indicated that primarily high paternal overprotection and low maternal care significantly $(\mathrm{P}<0.05)$ predicted $14 \%$ and $15 \%$ of severity and frequency of psychological symptoms, respectively.

Conclusion: Parental bonding components have a significant relationship with general suffering scales. Affectionless control parenting style with low care and high overprotection is the most traumatic way of parental interaction in childhood and adolescence.

\section{Introduction}

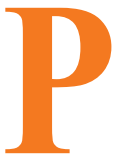

arental bonding can be described as an attachment between the child and parents. In other words, parental bonding is an emotional bond between infants and their primary caregivers. This bonding influences the future social, cognitive, and emotional aspects of the children. Parents become principal attachment figures if they provide most of the child care and related social in- teraction. According to Bowelby (1969), attachment is determined by the parent's attitude and behavior toward the infant's needs (Tam \& Yeoh, 2008). Sensitive and responding parents develop a secure attachment with their children. In contrast, parents who often neglect or reject their child's need for attention have an insecure attachment with their children.

The type of attachment between the parent and child plays a crucial role in the development of the child. Ac-

* Corresponding Author:

Behrooz Dolatshahi, PhD

Address: Substance Abuse and Dependence Research Center, University of Social Welfare and Rehabilitation Sciences, Tehran, Iran

Tel: +98 (21) 22180045

E-mail: b.dolat95@gmail.com 
cordingly, disturbances in parental bonding are linked with the development of disorders later in life. A number of studies have found that secure attachment and positive bonding experiences are associated with greater welfare, increased coping resources, and higher perceived support in one's community. On the other hand, insecure attachment has been reported to be related to psychopathology adjustment difficulties and suicidal tendency (Rikhye et al., 2008; Bagheriyazdi, Bolhari, \& Shahmohammad, 1994).

Positive bonding experiences are dependent on several factors, including nurturance, affection, ease of access, protection, support, and encouragement from caregivers, and are influenced by parent-child attributes and characteristics of their relationship (Bagheriyazdi et al., 1994). Parker and colleagues have proposed that bonding experiences with parents may be influenced by two fundamental dimensions of parenting, i.e. "care" and "overprotection". The parental care has two poles, measuring parental warmth, affection, and involvement versus coldness, rejection, detachment and aloofness, respectively. The second dimension, overprotection measures psychological control, infringement, and imposition versus encouragement of autonomy and self-sufficiency (Rikhye et al., 2008).

Several studies have indicated that poor parental bonding leads to the development of inappropriate coping skills, rendering the individual vulnerable to stress and affective illness (Kraaij et al, 2003; Matheson et al., 2005). Infurna et al. (2016) have found evidence of a transgenerational effect of parental bonding in female adolescents with borderline personality disorder compared with other clinical control subjects (Infurna et al., 2016). Low parental bonding and affectionless control quadrant was the most common quadrant in persons with a history of suicidal thoughts and suicidal acts (Singh, Manjula \& Philip, 2012). Low parental care has been reported to be associated with a high risk of mental disorders, e.g., anxiety, depression, drug and alcohol abuse and antisocial personality disorder (Enns, Cox, \& Clara, 2002).

Perceived poor maternal care and maternal overprotection are associated with emotional distress such as anxiety and depression, hoarding in women with OCD, and children's aggression and delinquency (Williams, Harfmann, Ingram, Hagan, \& Kramer, 2015; Chen et al., 2017; Fazeli Mehrabadi et al., 2012). Moreover, low maternal care reportedly predicted anxiety, depression, alcohol abuse, and secondary psychopathy (Kimbrel, Nelson-Gray \& Mitchell, 2007). While the affectionless control parental bonding identified by low care and high overprotection has been implicated as a risk factor for depression, many studies have found that in comparison with overprotection, the lack of care, particularly mother care, may be the most important factor in the development of depressive symptoms (Rikhye et al., 2008).

Tetley et al. (2014) have found that women with eating disorders typically reported parental care and higher overprotection. Rommel et al. (2012) have indicated that maternal and paternal overprotection negatively influenced the emotional awareness of obese patients such that emotional awareness positively influenced their emotional eating. Low parental overprotection predicted internet addiction among addicted behavioral studies (Chen, Chen, Gau, 2015), and maternal and paternal overprotection and ambivalent attachment were the best predictors of sexual addiction, differentiating 72.9 percent of sexual addicts from the control group (Zahedian, Mohammadi \& Samani, 2011).

Researchers who specifically studied the father-child relationship indicated that the absence of father's warmth and overprotection increase the demand for help in teenagers with affective disorders (Schofild et al., 2012). Mallers et al. (2010) also found that the quality of father-son relationship is related to the son's emotional responses to daily stresses in adulthood (Mallers, Charles, Neupert, \& Almeida, 2010). Behavioral modeling confirms the relationship between paternal overprotection and externalized behaviors (Fazeli Mehrabadi et al., 2012).

While most previous studies have investigated the effect of parental bonding on the psychopathology in clinical populations of adults, very little is known about the relationship between parental bonding and mental health in normal populations. The present study was aimed at assessing the relationship between parental bonding and type and severity of psychopathology in normally functioning students. In this study, we investigated the influence of the different factors of paternal and maternal bonding (care and overprotection) on the development of several mental disorders and examined their relationship with the severity and frequency of psychological symptoms in order to explore the vulnerability of the normal population to mental disorders. Determining the fundamental and important factors in each mental disorder and symptoms would lead us to constructive clinical implications for working with patients.

\section{Methods}

The present research used the cross-sectional design. The statistical population included the students of the Tabriz University who were studying M.S and B.S and living in the dormitory in 2011-2012 academic years. For 
sample selection, multi-stage cluster sampling was used. For this, the university students were divided into two clusters based on the girls' and boys' dormitory, and then 3 dormitories were selected randomly from each cluster. In each dormitory, 2 floors and 10 rooms were randomly selected, and finally, in each room, the volunteer students were asked to complete two questionnaires, i.e. Parental Bonding Instrument (PBI) and Symptom Check list-90 Revised (SCL-90-R), which are described in the below subsections. A total of 361 students ( 205 boys- 156 girls) completed the questionnaires.

The sample size was estimated using the Cohen's table. Accordingly, questionnaires were given to 400 students, and then invalid and incomplete questionnaires were excluded from the analysis. Finally, the obtained data were analyzed by Pearson correlation coefficient and hierarchical regression via SPSS v.16 software. Participation in the present study was voluntary, and the participants and their information were kept anonymous. The participants could leave the study at any time if they feel uncomfortable. After the research was over, the participants were allowed to discuss the procedure and findings with the psychologist. They were given a general idea of the aim of the research, and their roles in the research were explained.

The Parental Bonding Instrument (PBI) is a 25-item questionnaire that asks the respondents to rate the attitudes and behaviors of their parents during their first 16 years of life with them. The care dimension of the PBI reflects parental warmth and interest in contrast to indifference and rejection. The overprotection dimension of the PBI reflects parental over-control and the fostering of dependency in contrast to the encouragement of autonomy. Two identical forms ( 1 for each parent) were completed by each participant. Using a four-point scale, the parent figure is rated according to whether he or she is "very like" the description, "moderately like", "moderately unlike" or "very unlike" (Rigby, Slee, \& Martin, 2007). The PBI has been shown to be stable over a 20 year period in a nonclinical population and is resistant to the effects of life experiences and mood state (Wilhelm, Niven, Parker \& Hadzi Pavovic, 2005).

Based on the scores and subscales of parental care and parental overprotection, the individual may fall in one of the four categories: 1. Optimal child rearing (high carelow overprotection); 2. Controlling with affection (high care-high overprotection); 3. Controlling without affection (Low care-high overprotection); and 4. Neglectful child rearing (Low care-low overprotection). The authors of the questionnaire have reported a reliability value of 0.76 and 0.83 for overprotection and care scales, respec- tively, on re-test. The validity of the questionnaire is reportedly 0.76 for care and 0.63 for overprotection. The authors have reported Cronbach's $\alpha$ values of 0.93 and 0.87 for parental overprotection and care, respectively (Parker, 1987). Shaker and Homeyli (2011) found Cronbach's $\alpha$ to be 0.74 for overprotection and 0.78 for care (Shaker \& Homeyli, 2011). In this study, we found Cronbach's $\alpha$ value of $90 \%$ and $88 \%$ for paternal care and maternal care and $85 \%$ and $80 \%$ for paternal overprotection and maternal overprotection, respectively.

The Symptom Checklist-90 Revised (SCL-90-R) is a popular 90-item self report inventory designed to reflect the psychological symptoms in psychiatric patients. Each question measures the extent of symptoms during the last 7 days. The SCL-90-R includes nine subscales and three global indexes: Somatization (SOM), Obsessive Compulsive (OC), Interpersonal Sensitivity (IS), Depression (DEP), Anxiety (ANX), Hostility (HOS), Phobic Anxiety (PHOB), Paranoid Ideation (PAR), and Psychoticism (PSY). The Global Severity Index (GSI) assesses the extent or depth of psychiatric distress, the Positive Symptom Total (PST) counts the number of psychiatric symptoms, and the Positive Symptom Distress Index (PSDI) represents the intensity of symptoms. The retest reliability (correlation coefficients) of the scales fall between $r=0.7-0.9$ in the US and German 'functional' samples (Schauenburg \& Strack, 1999).

Derogatis, Rickels \& Rock (1976) found a high convergent validity for SCL-90. Peak correlations were observed with eight of the nine scales, with secondary patterns of correlations having high interpretative consistency. In 1994, Bagheri and his colleges validated the Iranian version of SCL-90-R. They estimated the validity, sensitivity, specificity, and reliability to be $97 \%, 94 \%$, $98 \%$, and 96\%, respectively (Bagheri yazdi et al., 1994). In our study, the Cronbach's $\alpha$ value of this questionnaire was $97 \%$.

\section{Results}

As mentioned earlier, the participants of this study included 205 male and 156 female students from the Tabriz University. They were aged between 18 to 39 years $($ mean $=22.29$, standard deviation $=2.603$ ). Table 1 shows the mean and standard deviation of the research variables. We used the Pearson correlation coefficient, as shown in Table 2. Both paternal and maternal components have a significant relationship with the SCL-90-R indexes. Maternal and paternal cares have a negative correlation with SCL-90-R. Paternal overprotection has 
Table 1. Mean and standard deviation of parental bonding components

\begin{tabular}{|c|c|c|c|}
\hline Scale & Subscale & Mean & Standard Deviation \\
\hline \multirow{5}{*}{ Parental bon } & Maternal care & 26.58 & 6.808 \\
\hline & Maternal overprotection & 14.77 & 6.464 \\
\hline & & & \\
\hline & Paternal care & 23.82 & 7.793 \\
\hline & Paternal overprotection & 13.82 & 7.584 \\
\hline
\end{tabular}

the strongest relationship with SCL-90-R, followed by maternal care.

As shown in Table 2, parental bonding components have a significant correlation with the psychological symptoms of the children. The expected psychological symptoms have a significant and negative relationship with maternal and paternal care and a significant and positive relationship with overprotection. This indicates that low parental care and high parental control and overprotection are related to psychological symptoms. In this study, parental bonding components were considered as predictor variables while and severity (PSDI) and frequency (PST) of psychological symptoms were considered as dependent variables. We used the hierarchical regression to analyze the relationship between the variables. The results are shown in Table 3. According to Table $3,14 \%$ of severity and $15 \%$ of psychological symptoms frequency were significantly $(\mathrm{P}<0.05)$ predicted by parental bonding components. This result indicates that primarily paternal overprotection and maternal care can significantly predict severity and frequency of psychological symptoms.

\section{Discussion}

Both paternal and maternal bonding plays an important role in the development of a child. As expected, we found that low parental care and high overprotection were associated with psychological symptoms in children. In this regard, the relationship between paternal and maternal bonding and psychological symptoms experiences was elucidated, and this relationship with maternal care was found to be stronger (Table 4). Ishizaki,

Table 2. Mean and standard deviation of psychological symptoms, severity, frequency and GSI

\begin{tabular}{|c|c|c|}
\hline Scales & Mean & Standard Deviation \\
\hline Somatization & 9.25 & 7.976 \\
\hline Obsessive compulsive & 10.42 & 7.211 \\
\hline Interpersonal sensitivity & 8.55 & 6.401 \\
\hline Depression & 13.61 & 10.289 \\
\hline Anxiety & 8.61 & 6.780 \\
\hline Hostility & 4.80 & 4.142 \\
\hline Phobic anxiety & 4.11 & 4.586 \\
\hline Paranoid & 7.75 & 5.221 \\
\hline Psychotism & 8.15 & 6.745 \\
\hline GSI & 0.91 & 0.611 \\
\hline PSDI & 81.23 & 54.113 \\
\hline PST & 43.77 & 20.465 \\
\hline
\end{tabular}


Table 3. Correlation coefficients of parental bonding components and total suffering indexes of SCL-90-R

\begin{tabular}{|c|c|c|c|}
\hline Scales & PST & PSDI & GSI \\
\hline Maternal care & $-0.280^{* *}$ & $-0.269^{* *}$ & $-0.268^{* *}$ \\
\hline Paternal care & $-0.205^{* *}$ & $-0.186^{* *}$ & $0.186^{* *}$ \\
\hline Maternal overprotection & $0.243^{* *}$ & $0.230^{* *}$ & $0.230^{* *}$ \\
\hline Paternal overprotection & $0.371^{* *}$ & $0.346^{* *}$ & $0.346^{* *}$ \\
\hline
\end{tabular}

Table 4. Correlation coefficients of parental bonding components and psychological symptoms

\begin{tabular}{|c|c|c|c|c|}
\hline & Maternal Care & Paternal Care & Maternal Overprotection & Paternal Overprotection \\
\hline Somatization & $-0.217^{* *}$ & $-0.168^{* *}$ & $0.178^{* *}$ & $0.258^{* *}$ \\
\hline Obsessive compulsive & $-0.221^{* *}$ & $-0.143^{* *}$ & $0.192^{* *}$ & $0.297^{* *}$ \\
\hline Interpersonal sensitivity & $-0.283^{* *}$ & $-0.188^{* *}$ & $0.194^{* *}$ & $0.302^{* *}$ \\
\hline Depression & $-0.279^{* *}$ & $-0.176^{* *}$ & $0.172^{* *}$ & $0.277^{* *}$ \\
\hline Anxiety & $-0.248^{* *}$ & $-0.201^{* *}$ & $0.220^{* *}$ & $0.346^{* *}$ \\
\hline Hostility & $-0.161^{* *}$ & $-0.160^{* *}$ & $0.153^{* *}$ & $0.264^{* *}$ \\
\hline Phobic anxiety & $-0.258^{* *}$ & $-0.141^{* *}$ & $0.246^{* *}$ & $0.314^{* *}$ \\
\hline Paranoid & $-0.158^{* *}$ & $-0.157^{* *}$ & $0.208^{* *}$ & $0.316^{* *}$ \\
\hline Psychotism & $-0.246^{* *}$ & $-0.113^{* *}$ & $0.215^{* *}$ & $0.292^{* *}$ \\
\hline
\end{tabular}

Nagaham \& Kaneko (2013) indicated that maternal care is a predictor of self-confidence in individuals during their developmental period; high maternal care and intimacy increase self-confidence and decrease the tendency to self-incapability.
Kimbrel et al. (2008) studied the role of maternal parenting style in predicting psychopathology in 181 college students. They found that low maternal care after demographic variables predicted a wide range of psychological symptoms. They showed that mater-

Table 5. Hierarchical regression summery for predicting severity and frequency of psychological symptoms

\begin{tabular}{ccccccc}
\hline \multirow{2}{*}{ Scales } & \multicolumn{3}{c}{ PSDI } & \multicolumn{3}{c}{ PST } \\
\cline { 2 - 7 } & Adjus R $\mathbf{R}^{2}$ & B & Sig. & Adjus R $\mathbf{R}^{2}$ & B & Sig. \\
\hline Parental bonding & 0.14 & & 0.000 & 0.159 & & 0.000 \\
Maternal care & & -0.196 & 0.001 & -0.198 & 0.001 \\
Paternal care & 0.057 & 0.345 & 0.049 & 0.409 \\
Maternal overprotection & -0.005 & 0.937 & -0.008 & 0.892 \\
\hline Paternal overprotection & & 0.314 & 0.000 & 0.337 & 0.000 \\
\hline
\end{tabular}

A. Predictor variables: Parental bonding component

B. Dependent variable: Severity (PSDI) and frequency (PST) of psychological symptom 
nal care and overprotection predict psychopathology. However, this finding is in contrary to our findings that maternal overprotection significantly can just predict somatization symptoms.

Studies that used PBI found a relationship weak mental health and low parental care and high parental overprotection (Craissati et al., 2002; Martin, Bergen, Roeger, \& Allison, 2004). The fact that inappropriate parental bonding subjects a person to mental disorders is consistent with many previous studies. For instance, the findings of Enns et al. (2002) indicate that persistent lack of care is associated with adulthood mental damages (Chen et al., 2015). Moreover, they reported that excessive parental sensitivity about care and overprotection may lead to the development of anxiety symptoms. In addition, other previous studies also reported similar findings, which are in line with our present study (Schofild et al., 2012; Rikhye, 2008). Parker et al. (1997) also indicated that generalized anxiety disorder is significantly related to inappropriate parental bonding (Rommel et al., 2012).

Our study's results showed that paternal overprotection has the strongest relationship with GSI, sign of depth, total symptoms, and global psychological distress. Parental overprotection and control can have an important role in psychopathology; its relationship with anxiety was found to be the strongest. Shaker and Homeyli (2011) reported that a general picture of parental bonding in their clinical groups reveals that patients with anxiety mostly report optimal child rearing or controlling without affection while patients with depression mostly report neglectful child rearing, particularly paternally, and maternal controlling without affection. Other studies have also reported similar findings (Narita et al., 2000; Mancini, D'Olimpio, Prunetti, Didonna, \& Del Genio, 2000; Yoshizumi, et al., 2007; Myhr, Sookman, \& Pinard, 2004).

This finding corroborates that the predictive nature of low care is the main parameter reported by depressed patients. Shaker and Homeyli (2011) found that paternal neglect, alongside high overprotection and low care by both parents, is an important factor in the development of depression. Most patients with obsession report appropriate parental bonding while a few of them reported neglectful child rearing or controlling without affection (Shaker \& Homeyli, 2011; Craissati, McClurg \& Browne, 2002). Shaker and Homeyli (2011) indicated that patients with obsessive-compulsive disorder symptoms report the highest parental care, those with generalized anxiety symptoms report the highest parental overprotection, and patients with depression symptoms report the lowest overprotection and care.
Most previous studies have reported a controlling parenting without affection as a predictor of depression, which is similar to our study (Shaker \& Homeyli, 2011; Narita et al., 2000; Mancini, D Olimpio and Del Genio, 2000; Yoshizumi, et al., 2007; Myhr, Sookman, \& Pinard, 2004). We found that high paternal overprotection and low maternal care can significantly predict $14 \%$ and $15 \%$ of severity and frequency of psychological symptoms, respectively (Table 5). Finally, it can be concluded that affectionless control style is the most traumatic parenting style that can predict mental health problems in the future. According to our results, controlling fathers and affectionless and cold mothers develop patient and groaning children. Future longitudinal studies may reveal the effect of specific parental bonding characterizations on children psychopathology. Following the finding that parental behavior plays a crucial role in children's psychopathology, there seems to be a great need for teaching parents the basic principles of child upbringing.

The results of our study had some limitations. First, the PBI measures parenting behaviors retrospectively (during the first 16 years of life); thus, there is the possibility of recall bias. Second, this study was not on the basis of direct observation and relied on offspring report of parenting, which could have had an impact on the results obtained. Third, parental care and overprotection are two dimensions of parenting; however, there are other important aspects of parenting or family dynamics that were not assessed in this study. Fourth, regarding the generalizability of findings, all participants are students, which may reflect the different types of psychopathology and different parental bonding experiences from other populations. Fifth, it was cross-sectional study due to which we cannot make any causal claims.

Given the findings and limitations, future research should repeat this study with wider samples and longitudinal designs. Beside, different scales and methods of measurements can be used to examine parental bonding and parent-child relationship. Future research can also take into account the other important aspects of parenting or family dynamics affecting parent-child bonding and relationship.

\section{Acknowledgments}

We appreciate all participants in this study and those who helped us in conducting this research. This research was extracted from the MSc. thesis of the first author, in the Department of Clinical Psychology, University of Social Welfare and Rehabilitation Sciences. 


\section{Conflict of Interest}

The authors declared no conflicts of interest.

\section{References}

Bagheriyazdi, A., Bolhari, J., \& Shahmohammad, D. (1994). [An epidemiological study of psychological disorders on a rural area (Meibod, Yazd) in Iran (Persian)]. Iranian Journal of Psychiatry and Clinical Psychology, 1(1), 32-41.

Chen, D., Bienvenu, O. J., Krasnow, J., Wang, Y., Grados, M. A., Cullen, B., et al. (2017). Parental bonding and hoarding in obsessive compulsive disorder. Comprehensive Psychiatry, 73, 43-52. doi: 10.1016/j.comppsych.2016.11.004

Chen, Y. L., Chen, S. H., \& Gau, S. S. F. (2015). ADHD and autistic traits, family function, parenting style, and social adjustment for Internet addiction among children and adolescents in Taiwan: A longitudinal study. Research in Developmental Disabilities, 39, 20-31. doi: 10.1016/j.ridd.2014.12.025

Craissati, J., McClurg, G., \& Browne, K. (2002). The parental bonding experiences of sex offenders: A comparison between child molesters and rapists. Child Abuse E Neglect, 26(9), 90921. doi: 10.1016/s0145-2134(02)00361-7

Derogatis, L. R., Rickels, K., \& Rock, A. F. (1976). The SCL-90 and the MMPI: A step in the validation of a new self-report scale. The British Journal of Psychiatry, 128(3), 280-9. doi: 10.1192/ bjp.128.3.280

Enns, MW., Cox, Bj., Clara, I. (2002). Parental bonding and adult psychopathology: Results from the US national comorbidity survey. Psychological Medicine, 32(6), 997-1008. doi: 10.1017/ s0033291702005937

Fazeli Mehrabadi, A., Mohammadi, S., Aghababaei, N., Izadpanah, SH., Panaghi, L., Ghadiri F. (2012) [Parental bonding and mental health: The role of gender (Persian)]. Developmental Psychology: Iranian Psychologists, 8(30), 197-206.

Infurna, M. R., Fuchs, A., Fischer Waldschmidt, G., Reichl, C., Holz, B., Resch, F., et al. (2016). Parents' childhood experiences of bonding and parental psychopathology predict borderline personality disorder during adolescence in offspring. Psychiatry Research, 246, 373-8. doi: 10.1016/j.psychres.2016.10.013

Ishizaki, Y., Nagahama, T., \& Kaneko, K. (2013). Mental health of mothers and their premature infants for the prevention of child abuse and maltreatment. Health, 5(3), 612-6. doi: 10.4236/health.2013.53a081

Kimbrel, N. A., Nelson Gray, R. O., \& Mitchell, J. T. (2007). Reinforcement sensitivity and maternal style as predictors of psychopathology. Personality and Individual Differences, 42(6), 1139-49. doi: 10.1016/j.paid.2006.06.028

Kraaij, V., Garnefski, N., de Wilde, E. J., Dijkstra, A., Gebhardt, W., Maes, S., et al. (2003). Negative life events and depressive symptoms in late adolescence: Bonding and cognitive coping as vulnerability factors. Journal of Youth and Adolescence, 32(3), 185-93. doi: 10.1023/a:1022543419747
Mallers, M. H., Charles, S. T., Neupert, S. D., \& Almeida, D. M. (2010). Perceptions of childhood relationships with mother and father: Daily emotional and stressor experiences in adulthood. Developmental Psychology, 46(6), 1651-61. doi: 10.1037/ a0021020

Mancini, F., D'Olimpio, F., Prunetti, E., Didonna, F., \& Del Genio, M. (2000). Parental bonding: Can obsessive symptoms and general distress be predicted by perceived rearing practices. Clinical Psychology \& Psychotherapy, 7(3), 201-8. doi: 10.1002/1099-0879(200007)7:3<201::aid-cpp241>3.0.co;2-k

Martin, G., Bergen, H. A., Roeger, L., \& Allison, S. (2004) Depression in young adolescents. The Journal of Nervous and Mental Disease, 192(10), 650-7. doi: 10.1097/01. nmd.0000142028.10056.c6

Matheson, K., Kelly, O., Cole, B., Tannenbaum, B., Dodd, C., \& Anisman, H. (2005). Parental bonding and depressive affect: The mediating role of coping resources. British Journal of Social Psychology, 44(3), 371-95. doi: 10.1348/014466605x37477

Myhr, G., Sookman, D., \& Pinard, G. (2004). Attachment security and parental bonding in adults with obsessive compulsive disorder: A comparison with depressed out patients and healthy controls. Acta Psychiatrica Scandinavica, 109(6), 447-56. doi: 10.1111/j.1600-0047.2004.00271.x

Narita, T., Sato, T., Hirano, S., Gota, M., Sakado, K., \& Uehara T. (2000). Parental child rearing behavior as measured by the Parental Bonding Instrument in a Japanese population: Factor structure and relationship to a lifetime history of depression. Journal of Affective Disorders, 57(1-3), 229-34. doi: 10.1016/ s0165-0327(99)00071-3

Parker, G. (1987). Parental representations of neurotic and endogenous depressives. Journal of Affective Disorders, 13(1), 75-82. doi: 10.1016/0165-0327(87)90076-0

Rigby, K., Slee, P. T., \& Martin, G. (2007). Implications of inadequate parental bonding and peer victimization for adolescent mental health. Journal of Adolescence, 30(5), 801-12. doi: 10.1016/j.adolescence.2006.09.008

Rikhye, K., Tyrka, A. R., Kelly, M. M., Gagne, G. G., Mello, A. F., Mello, M. F., et al. (2008). Interplay between childhood maltreatment, parental bonding, and gender effects: Impact on quality of life. Child Abuse \& Neglect, 32(1), 19-34. doi: 10.1016/j.chiabu.2007.04.012

Rommel, D., Nandrino, J. L., Ducro, C., Andrieux, S., Delecourt, F., \& Antoine, P. (2012). Impact of emotional awareness and parental bonding on emotional eating in obese women. Appetite, 59(1), 21-6. doi: 10.1016/j.appet.2012.03.006

Schauenburg, H., \& Strack, M. (1999). Measuring psychotherapeutic change with the symptom checklist SCL90-R. Psychotherapy and Psychosomatics, 68(4), 199-206. doi: $10.1159 / 000012333$

Schofield, T. J., Conger, R. D., Donnellan, M. B., Jochem, R. Widaman, K. F., \& Conger, K. J. (2012). Parent personality and positive parenting as predictors of positive adolescent personality development over time. Merrill Palmer Quarterly, 58(2), 255-83. doi: 10.1353/mpq.2012.0008

Shaker, A., \& Homeyli, N. (2011). Comparing parental bonding and attachment styles in patients with obsessive compulsive disorder, generalized anxiety and depression. Journal of Jahrom University of Medical Sciences, 9(3), 19-25. 
Singh, S., Manjula, M., \& Philip, M. (2012). Suicidal risk and childhood adversity: A study of Indian college students. Asian Journal of Psychiatry, 5(2), 154-9. doi: 10.1016/j.ajp.2012.02.024

Tam, C. L., \& Yeoh, S. H. (2008). Parental bonding and parentchild relationship among tertiary students. Sunway Academic Journal, 5, 111-27.

Tetley, A., Moghaddam, N. G., Dawson, D. L., \& Rennoldson, M. (2014). Parental bonding and eating disorders: A systematic review. Eating Behaviors, 15(1), 49-59. doi: 10.1016/j.eatbeh.2013.10.008

Wilhelm,K. Niven, H,. Parker, G., Hadzi Pavovic, D. (2005). The stability of the parental bonding instrument over a 20 year period. Psychological Medicine, 35(3), 387-93. doi: 10.1017/ s0033291704003538

Williams, C. L., Harfmann, E. J., Ingram, R. E., Hagan, K. E., \& Kramer, N. M. (2015). Specificity of parental bonding and rumination in depressive and anxious emotional distress. Personality and Individual Differences, 79, 157-61. doi: 10.1016/j. paid.2015.01.055

Yoshizumi, T., Murase, S., Murakami, T., \& Takai, J. (2007). Dissociation as a mediator between perceived parental rearing style and depression in an adult community population using college students. Personality and Individual Differences, 43(2), 353-64. doi: 10.1016/j.paid.2006.12.010

Zahedian, S. F., Mohammadi, M., \& Samani, S. (2011). [The role of attachmet styles, parental bonding and self concept in sexual addiction (Persian)]. Journal of Clinical Psychology, 3(3), $65-73$ 